\title{
TESTS OF DOUBLE RAW HIDE BELTS.
}

\section{By John E. Hilleary.}

[A paper read at the Stated Meoting of the Franklin Institute, May 17, 1882.]

Having made some tests of new riveted double so-called "raw hide" (semi-tanned and fulled) belts on a 36 -inch new wooden pulley, with $180^{\circ}$ are of contact and tensions of 25 and 50 pounds per inch of belt width, I find them as follows:

With the grain side next the pulley (both grain sides were out, as is usual with tanned leather belts) the grip with 25 pounds tension per inch was 200 pounds, and with 50 pounds, 460 pounds. It thus seems that in the case of this 4-inch new double-fulled leather belt, on that new 36 -inch wooden pulley, with $180^{\circ}$ are of contact, doubling the tension more than doubled the grip, the latter being as 100 to 230 .

Comparing the grip of the double belt with that of a single belt of the same material, under the same conditions (grain side to), we find as follows:

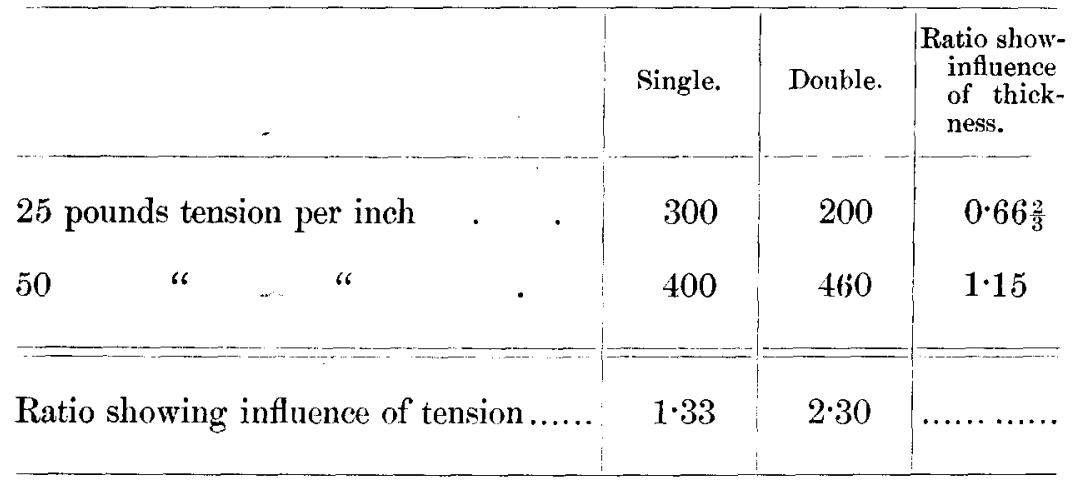

These results are curious, and would indicate, without looking into the matter, that with new riveted double " fulled" belts on 36 -inch new wooden pulleys, with $180^{\circ}$ contact and tensions of 25 and 50 pounds per inch width--

(1) With light tensions a double belt will not grip as well as a single one. 
(2) With heavy tensions a double belt will drive more than a single one.

(3) Both single and double belts drive better with heavy than with light tensions.

(4) The influence of tension is more marked with double than with single belts.

In reference to "raw hide" belts there are some that get hard after running a while, while others remain pliable and elastic. By "elastic" I do not mean that they stretch so as to necessitate being taking up constantly; for a belt that needs taking up every little while is not elastic. If it were elastic, the local extension in length while in contact with the pulley would be counteracted in each portion as soon as it got round to slack side.

I want to be particularly understood as repudiating, as yet, any general formulæ or statements covering the working of belts on pulleys where all the conditions are not stated. Some of my notes may seem to contain needless repetitions, but they are cautionary limitations. If, after making my tests of new single leather belts on new cast-iron pulleys, I had formulated the rule that new leather belts drive best flesh side to the pulley, I should have been badly "out" on the subject of semi-tanned leather belts.

New Determination of Joule's Equivalent.-Cantoni and Gerosa have determined the mechanical equivalent of heat by a series of experiments in which they substituted mercury for water. Its great thermal conductibility, and the relative invariability of its specific heat at the low temperatures which they employed, induced them to make the substitution. The method of experimenting consisted in the sudden arrest of a mass of mercury, falling from a given height and consequently provided with a known amount of dynamic energy. The increase of temperature at each experiment was carefully measured, and the dynamic equivalent of caloric dednced by a simple calculation. The mean of all the results is almost precisely the same as that which Joule obtained from his most satisfactory experiments. The agreement of the values which are furnished by two processes that are so distinct seems to give complete assurance of the accuracy of the results. C. Whole No. Vol. CXIV.-(Thtrd Series, Vol. lsixiv.) 